\title{
RESUMEN
}

\section{¿Continúan la nitrofurantoína y la fosfomicina como alternativas para el tratamiento de infecciones de las vías urinarias no complicadas en mujeres ecuatorianas? Una vigilancia a partir del inicio del milenio (2002-2018)}

\author{
Zurita, Jeannete 1,2,3*; Sevillano, Gabriela ${ }^{3}$; Paz y Miño, Arianne ${ }^{3}$ \\ ${ }^{1}$ Hospital Vozandes, Quito, Ecuador. \\ 2 Pontificia Universidad Católica del Ecuador, Facultad de Medicina, Quito, Ecuador. \\ ${ }^{3}$ Unidad de Investigaciones en Biomedicina, Zurita \& Zurita Laboratorios, Quito, Ecuador. \\ e-mail: jzurita@zuritalaboratorios.com
}

Palabras clave: Fosfomicina, infección de vías urinarias (IVU), mujeres, nitrofurantoína.

INTRODUCCIÓN: Escherichia coli es el patógeno más común causante de infecciones de vías urinarias (IVU) no complicadas. [1] El tratamiento empírico cuando la resistencia es menor al $20 \%$ es trimetoprima-sulfametaxole seguido de ciprofloxacino, también se recomienda fosfomicina y nitrofurantoína, obteniéndose los mismos resultados con un número reducido de efectos adversos.

OBJETIV0: Analizar la resistencia de fosfomicina y nitrofurantoína en la última década y considerar si aún pueden ser usados como tratamiento en IVU por $E$. coli no complicadas en mujeres $>15$ años.

MATERIALES Y MÉTODOS: Desde el año 2002 al 2018, se analizaron todas las E. coli aisladas de muestras de orina de mujeres $>15$ años que acudieron al Hospital Vozandes. Se utilizó el sistema WHONET para la obtención de los datos. Los criterios de interpretación fueron evaluados usando el CLSI. Se utilizó la prueba $\mathrm{X}^{2}$ para evaluar la significancia de los datos.

RESULTADOS: De un total de 32.032 E. coli, el $86,4 \%(27.684 / 32.032)$ pertenecieron a mujeres mayores de 15 años y el 70\% (19.348/27.684) a infecciones adquiridas en la comunidad. El $18 \%(3.474 / 19.348)$ fueron E. coli productoras de $\beta$-lactamasa de espectro extendido (BLEE). $\mathrm{Al}$ analizar las E. coli-BLEE, las alternativas de tratamiento se reducen a fosfomicina, nitrofurantoína por vía oral y amikacina $\mathrm{y}$ ertapenem por vía parenteral. La nitrofurantoína presentó resistencias variables entre 2002 $(7,3 \%)$ al $2018(7,6 \%)(p=0,27)$, mientras que la fosfomicina presentó una tendencia creciente desde el $2002(0 \%)$ al $2018(6,9 \%)(\mathrm{p}<0,05)$.

CONCLUSIONES: Existen cambios significativos en la sensibilidad a fosfomicina. Esto podría explicarse por el aparecimiento de plásmidos y el creciente uso de fosfomicina en la industria agropecuaria [2], poniendo en riesgo la utilidad de este antibiótico. Los cambios en la sensibilidad a nitrofurantoína, no fueron estadísticamente significativos. El tratamiento por vía oral de $E$. coli-BLEE urinaria continúan siendo fosfomicina y nitrofurantoína, con un $81,6 \%$ y $89,1 \%$ de sensibilidad, respectivamente. La presencia de $E$. coli-BLEE causante de IVU de la comunidad fue del $18 \%$ en contraste con otros estudios ecuatorianos que arrojan cifras mayores al 30\% o $50 \%$.

\section{REFERENCIAS:}

[1] Minardi D, D’Anzeo G, Cantoro D, Conti A, Muzzonigro G. Urinary tract infections in women: etiology and treatment options. Int J Gen Med. 2011; (4): 333-343. 
[2] Zeng Z, Lv L, Yang T, Lin D, Liu J. Detection of the plasmid-encoded fosfomycin resistance gene fosA3 in Escherichia coli of food-animal origin. J Antimicrob Chemother. 2013 ;68(4): 766-770. 